\title{
Poly(hydridocarbyne) as Highly Processable Insulating Polymer Precursor to Micro/Nanostructures and Graphite Conductors
}

\author{
Aaron M. Katzenmeyer, ${ }^{1}$ Yavuz Bayam,,${ }^{1,2}$ Logeeswaran VJ, ${ }^{1}$ Michael W. Pitcher, ${ }^{3}$ \\ Yusuf Nur, ${ }^{3}$ Semih Seyyidoğlu, ${ }^{3}$ Levent K. Toppare, ${ }^{3}$ A. Alec Talin, ${ }^{4}$ Huilan Han, ${ }^{5}$ \\ Cristina E. Davis, ${ }^{5}$ and M. Saif Islam ${ }^{1}$ \\ ${ }^{1}$ Department of Electrical and Computer Engineering, University of California at Davis, Davis, CA 95616, USA \\ ${ }^{2}$ Department of Computer Engineering, Sakarya University, 54178 Sakarya, Turkey \\ ${ }^{3}$ Department of Chemistry, Middle East Technical University, 06531 Ankara, Turkey \\ ${ }^{4}$ Sandia National Laboratories, Livermore, CA 94551, USA \\ ${ }^{5}$ Department of Mechanical and Aeronautical Engineering, University of California at Davis, Davis, CA 95616, USA \\ Correspondence should be addressed to M. Saif Islam, saif@ece.ucdavis.edu
}

Received 2 November 2008; Accepted 25 November 2008

Recommended by Rakesh Joshi

Carbon-based electronic materials have received much attention since the discovery and elucidation of the properties of the nanotube, fullerene allotropes, and conducting polymers. Amorphous carbon, graphite, graphene, and diamond have also been the topics of intensive research. In accordance with this interest, we herein provide the details of a novel and facile method for synthesis of poly(hydridocarbyne) (PHC), a preceramic carbon polymer reported to undergo a conversion to diamond-like carbon (DLC) upon pyrolysis and also provide electrical characterization after low-temperature processing and pyrolysis of this material. The results indicate that the strongly insulating polymer becomes notably conductive in bulk form upon heating and contains interspersed micro- and nanostructures, which are the subject of ongoing research.

Copyright () 2009 Aaron M. Katzenmeyer et al. This is an open access article distributed under the Creative Commons Attribution License, which permits unrestricted use, distribution, and reproduction in any medium, provided the original work is properly cited.

\section{Introduction}

Poly(hydridocarbyne) (PHC) is an $\mathrm{sp}^{3}$ hybridized random network carbon polymer, comprised of amonomeric unit containing one carbon-hydrogen and three carbon-carbon single bonds not unlike hydrogenated tetrahedral amorphous carbon ( $\mathrm{ta}-\mathrm{C}: \mathrm{H})$. Much interest was generated by the synthesis of this easily processable polymer and the report of its conversion to diamond and DLC by means of pyrolysis [1]. Diamond has been reported to have interesting electrical properties [2, 3] and applications in MEMS [4] and biology [5]. And ta-C:H has also been shown to be relevant to the electrical and biological communities in the form of protectivecoatings in magnetic disk memories [6] and a haemocompatible material [7], respectively.

\section{Experimental}

We developed a new method for the synthesis of PHC [8] which enables faster, easier production and makes this interesting material more accessible for research. The method of synthesis involves the electropolymerization of chloroform $\left(\mathrm{CHCl}_{3}\right)$ which proceeds as shown in Figure 1. $\mathrm{UV} /$ visible data collected during the polymerization are consistent with the production of a polycarbyne, namely PHC $[1,9,10]$. Transmission infrared spectroscopy shows no evidence of carbon-carbon double bonds, only carboncarbon single bond and carbon-hydrogen stretches.

It was found that the polymer could be annealed at $100^{\circ} \mathrm{C}$ for processing as a liquid, in addition to the known method of suspending it in tetrahydrofuran (THF) or toluene, without the loss of its electrically insulating nature after cooling; an $\sim|8 \mathrm{nA}|$ current was measured via probe station at room temperature for $|5 \mathrm{~V}|$ bias. Semiconductorlike behavior was observed in the $\mathrm{I}(\mathrm{V})$ as the sample was heated.

Pyrolysis of the $\mathrm{PHC}$ polymer was performed under constant Ar flow at $1000^{\circ} \mathrm{C}$ for 24 hours in a Thermolyne tube furnace. A blackened bulk material was produced 


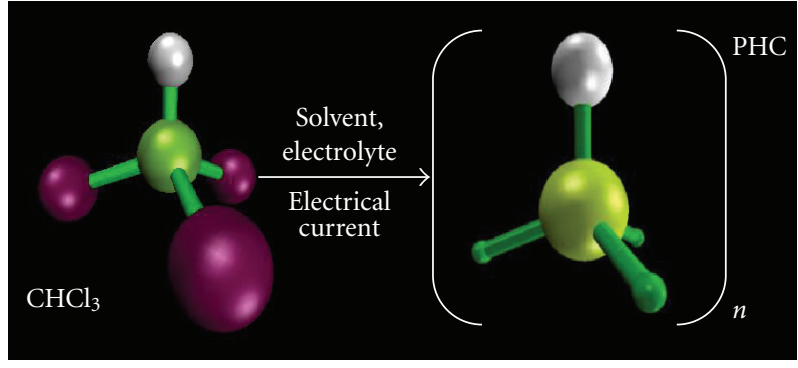

FIGURE 1: Electrolysis of chloroform $\left(\mathrm{CHCl}_{3}\right)$ in acetonitrile in the presence of tetrafluoroborate results in the production of $\mathrm{PHC}$.

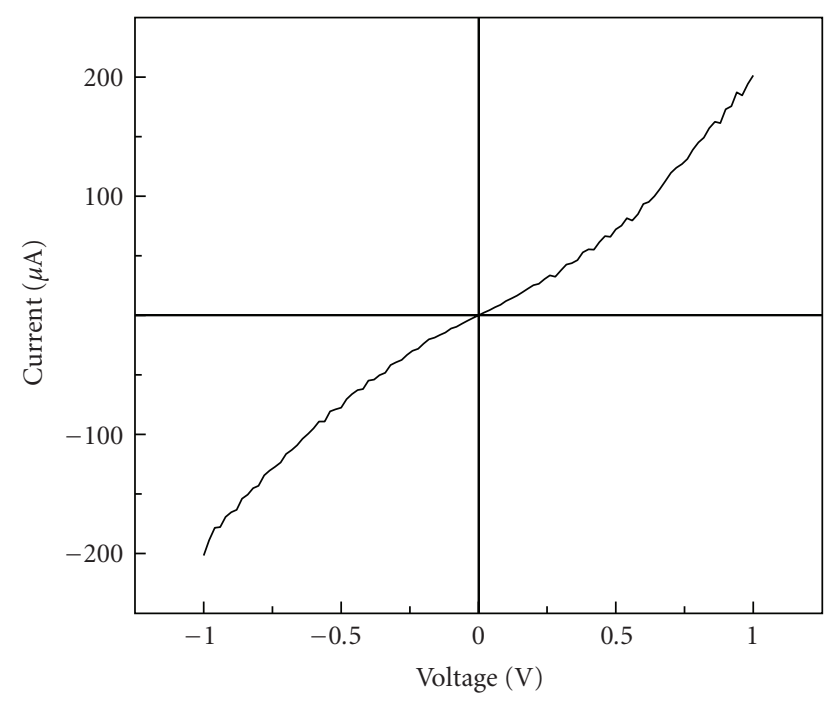

Figure 2: The I(V) plot for the pyrolyzed bulk shows a significant conductivity increase with respect to the annealed polymer.

which we electrically analyzed and characterized via Raman spectroscopy. This bulk material was probed (Figure 2) and found to be much more conductive than the annealed polymer despite exhibiting a nonlinear I(V) for $|\mathrm{V}|>0.25$. This increase in conductivity is rationalized by the formation of $\mathrm{sp}^{2}$ hybridized carbon constituents during pyrolysis (see the following).

\section{Raman Analysis}

A vast body of work has been published on Raman spectroscopy of carbon-based materials and the techniques used to fit Raman spectra using their individual constituent peaks, and this remains an active area of research as certain peak contributions are still debated or are of unknown origin. Nonetheless, a literature review revealed well-developed theory, which enabled us to curve fit our sample to good approximation.

Figure 3 shows the spectrum of our material plotted against that ofknown diamond, the intended product of the pyrolysis. The two broadened features seen in our spectrum occur in the vicinity of the well-known D (disordered) and G (graphite) peaks that occur around $1360 \mathrm{~cm}^{-1}$ and

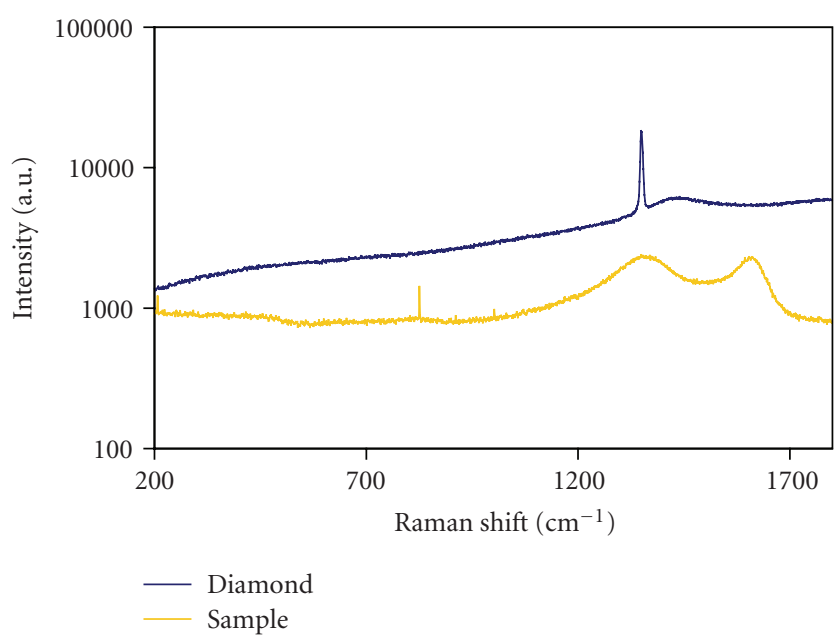

FIGURE 3: Raman spectra obtained for our pyrolyzed bulk sample and known diamond.

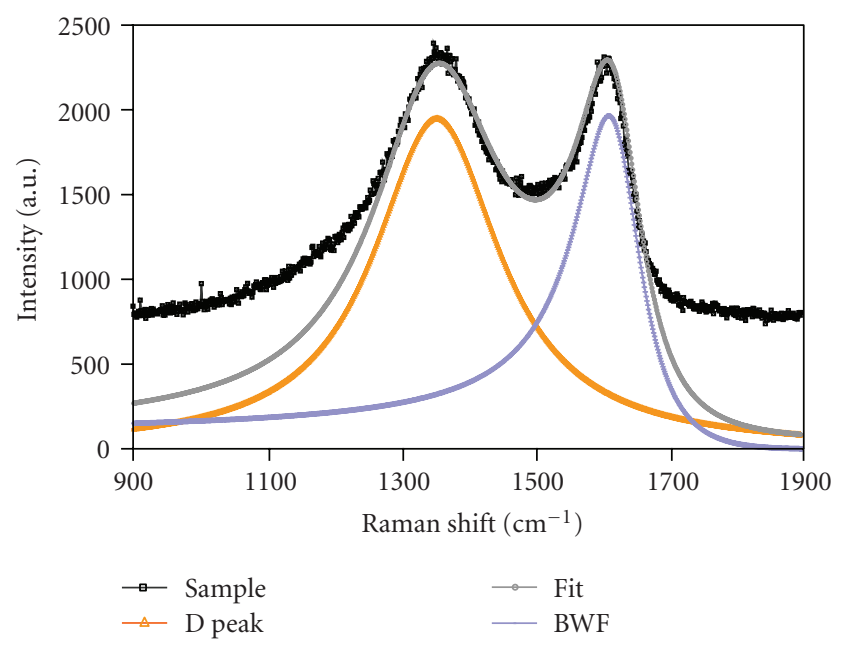

FIGURE 4: The Raman spectrum was fit using a Lorentzian function for the $\mathrm{D}$ peak. The other feature resulting from the combination of the $G$ and D' peaks can be represented by a BWF function.

$1560 \mathrm{~cm}^{-1}$, respectively, [11] in graphitic carbon materials and are particularly characteristic of microcrystalline graphite [12].

To elucidate this, we followed the convention of curve fitting the spectrum using a Lorentzian function for the D peak and a Breit-Wigner-Fano (BWF) function for the contribution near the $G$ peak (Figure 4). The motivation for the use of the BWF function lies in its ability to represent the merging of the $G$ and $D^{\prime}$ peaks, a phenomenon which occurs when the crystalline domains of a graphitic material are sufficiently small $[13,14]$. Due to the close fitting of our spectra using this methodology, we find the majority of the pyrolysis product is small-crystalline graphite, which explains the notable increase in conductivity after burning the PHC.

SEM did however reveal micro and nanostructures that were clearly morphologically distinct from the majority 


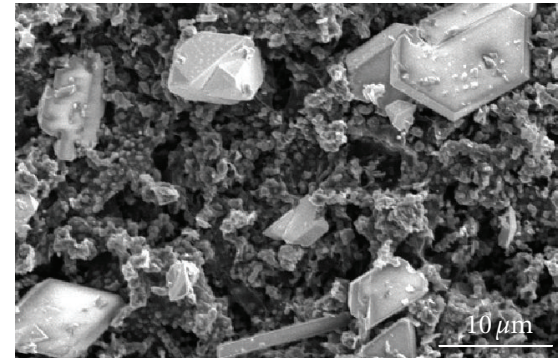

(a)

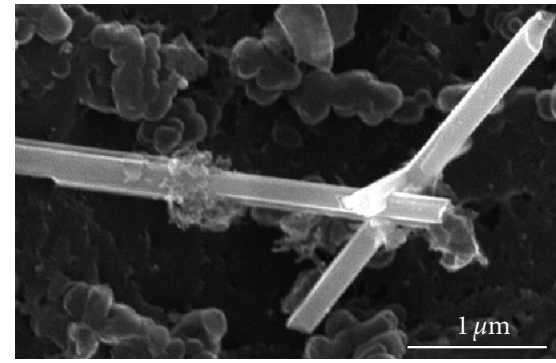

(c)

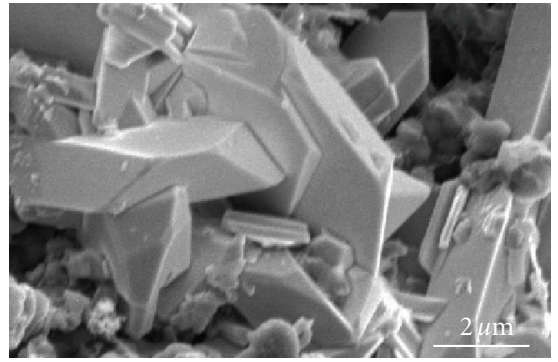

(b)

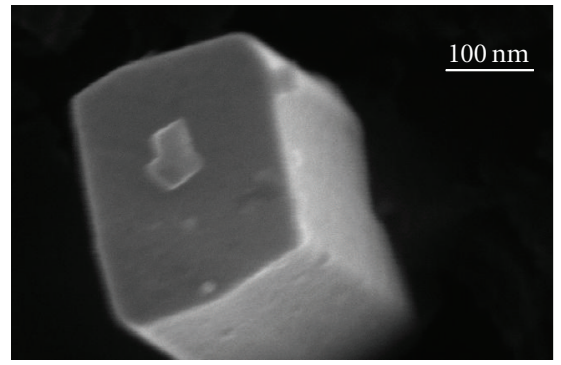

(d)

FIGURE 5: SEM micrographs of pyrolyzed PHC reveal micro and nanostructures interspersed in the bulk material.

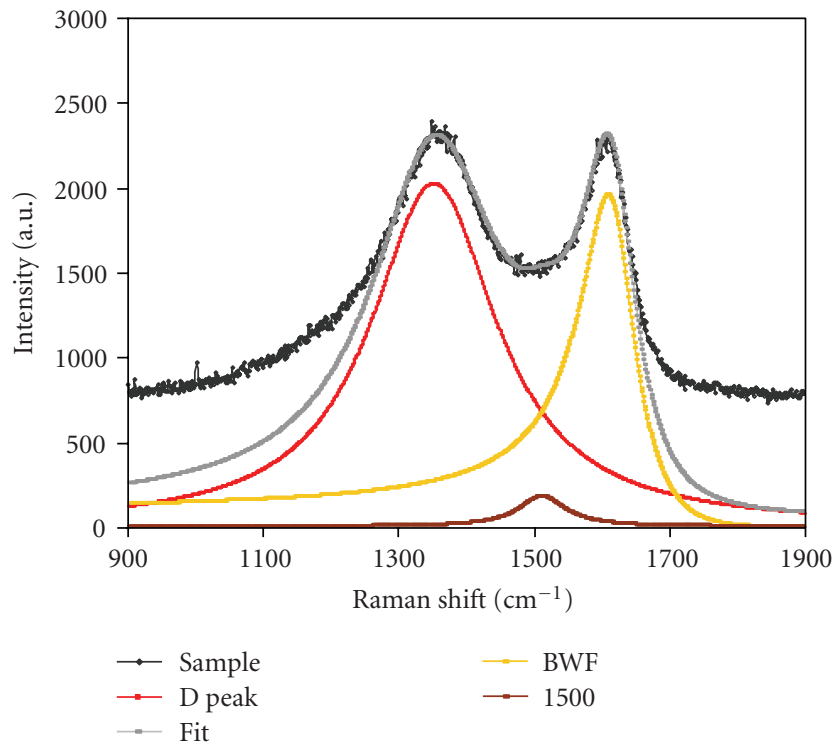

Figure 6: An improvement to the curve fit shown in Figure 4 can be made by adding another Lorentzian function at $1513 \mathrm{~cm}^{-1}$.

product (Figure 5). We attempted to account for this material by adding an additional Lorentzian to the curve-fitting procedure (Figure 6). The added Lorentzian is relatively small in magnitude is centered at $1513 \mathrm{~cm}^{-1}$, and improves the curve fitting of the sample's spectrum. Interestingly, an $\sim 1500 \mathrm{~cm}^{-1}$ peak in the spectrum of a related polymer precursor, poly(phenylcarbyne) $\left(\mathrm{C}_{6} \mathrm{H}_{5} \mathrm{C}\right)_{n}$, was observed after laser irradiation [15]. It has been suggested that such a peak could arise due to either impurity-carbon amorphous networks or amorphous networks of $\mathrm{sp}^{2}$ and $\mathrm{sp}^{3}$ carbon
[16]. However, only the latter suggestion is applicable to our method of pyrolysis. Therefore, the micro and nanostructures interspersed throughout the bulk may be comprised of such three- and four-fold coordinated amorphous carbon networks.

\section{Conclusion}

We have developed a novel and facile method for the synthesis of PHC, an easily processed, insulating polymer. Upon pyrolysis in inert atmosphere, we note a significant increase in conductivity of the product with respect to the precursor for the sample we investigated. The majority of the product analyzed was shown to be consistent with smallcrystalline graphite by way of curve fitting the sample's Raman spectrum. An improved curve fitting was found through incorporation of an additional minority constituent contributing to the spectrum at $\sim 1500 \mathrm{~cm}^{-1}$. This contribution may be the result of micro and nanostructures within the bulk observed by SEM.

\section{References}

[1] P. A. Bianconi, S. J. Joray, B. L. Aldrich, et al., "Diamond and diamond-like carbon from a preceramic polymer," Journal of the American Chemical Society, vol. 126, no. 10, pp. 3191-3202, 2004.

[2] J. Isberg, J. Hammersberg, E. Johansson, et al., "High carrier mobility in single-crystal plasma-deposited diamond," Science, vol. 297, no. 5587, pp. 1670-1672, 2002.

[3] C. E. Nebel, N. Yang, H. Uetsuka, T. Yamada, and H. Watanabe, "Quantized electronic properties of diamond," Journal of Applied Physics, vol. 103, no. 1, Article ID 013712, 5 pages, 2008. 
[4] J. K. Luo, Y. Q. Fu, H. R. Le, J. A. Williams, S. M. Spearing, and W. I. Milne, "Diamond and diamond-like carbon MEMS," Journal of Micromechanics and Microengineering, vol. 17, no. 7, pp. S147-S163, 2007.

[5] J.-I. Chao, E. Perevedentseva, P.-H. Chung, et al., "Nanometersized diamond particle as a probe for biolabeling," Biophysical Journal, vol. 93, no. 6, pp. 2199-2208, 2007.

[6] S. Pisana, C. Casiraghi, A. C. Ferrari, and J. Robertson, "Roughness evolution during growth of hydrogenated tetrahedral amorphous carbon," Diamond and Related Materials, vol. 15, no. 4-8, pp. 898-903, 2006.

[7] L. Zhang, M. Chen, Z. Li, D. Chen, and S. Pan, "Effect of annealing on structure and haemocompatibility of tetrahedral amorphous hydrogenated carbon films," Materials Letters, vol. 62, no. 6-7, pp. 1040-1043, 2008.

[8] M. W. Pitcher and L. K. Toppare, "A new industrially viable method for the production of polycarbynes," US patent no. 60831172, 2006.

[9] G. T. Visscher, D. C. Nesting, J. V. Badding, and P. A. Bianconi, "Poly(phenylcarbyne): a polymer precursor to diamond-like carbon," Science, vol. 260, no. 5113, pp. 1496-1499, 1993.

[10] G. T. Visscher and P. A. Bianconi, "Synthesis and characterization of polycarbynes, a new class of carbon-based network polymers," Journal of the American Chemical Society, vol. 116, no. 5, pp. 1805-1811, 1994.

[11] A. C. Ferrari, "Raman spectroscopy of graphene and graphite: disorder, electron-phonon coupling, doping and nonadiabatic effects," Solid State Communications, vol. 143, no. 1-2, pp. 4757, 2007.

[12] X. B. Yan, T. Xu, G. Chen, H. W. Liu, and S. R. Yang, "Effect of deposition voltage on the microstructure of electrochemically deposited hydrogenated amorphous carbon films," Carbon, vol. 42, no. 15, pp. 3103-3108, 2004.

[13] D. G. McCulloch, S. Prawer, and A. Hoffman, "Structural investigation of xenon-ion-beam-irradiated glassy carbon," Physical Review B, vol. 50, no. 9, pp. 5905-5917, 1994.

[14] R. Escribano, J. J. Sloan, N. Siddique, N. Sze, and T. Dudev, "Raman spectroscopy of carbon-containing particles," Vibrational Spectroscopy, vol. 26, no. 2, pp. 179-186, 2001.

[15] Y. F. Lu, S. M. Huang, and Z. Sun, "Raman spectroscopy of phenylcarbyne polymer films under pulsed green laser irradiation," Journal of Applied Physics, vol. 87, no. 2, pp. 945951, 2000.

[16] R. J. Nemanich, J. T. Glass, G. Lucovsky, and R. E. Shroder, "Raman-scattering characterization of carbon bonding in diamond and diamond like thin-films," Journal of Vacuum Science and Technology A, vol. 6, no. 3, pp. 1783-1787, 1988. 



The Scientific World Journal

Submit your manuscripts at

http://www.hindawi.com

\section{World Journal}

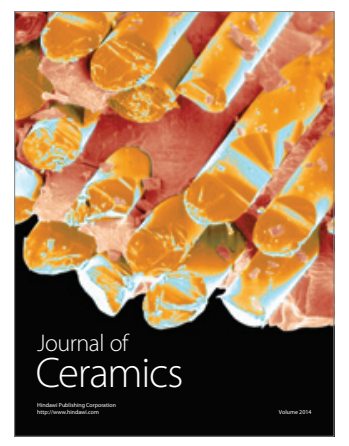

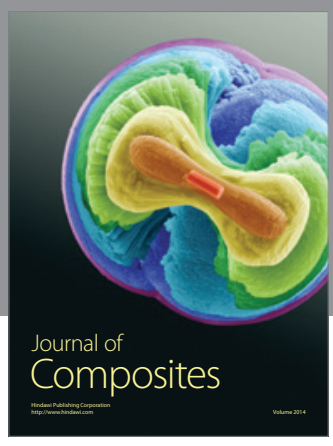
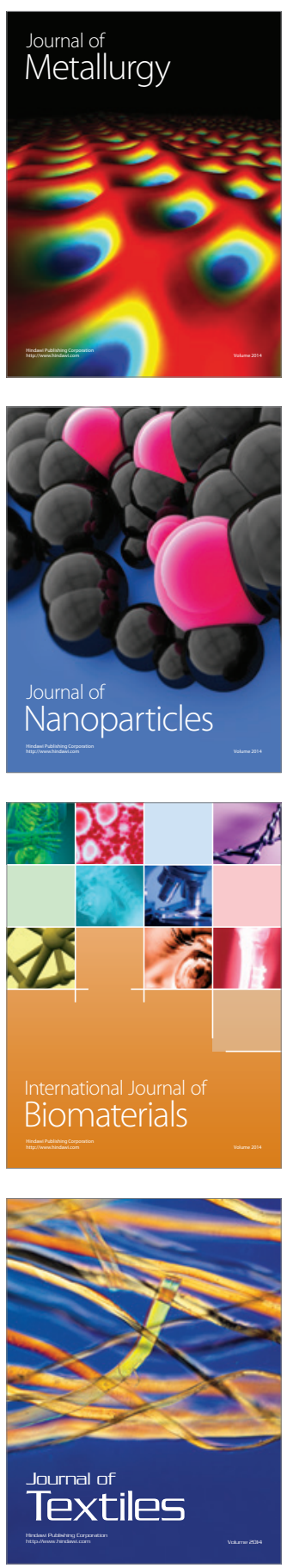